\title{
Glutamine and glutamic acid enhance thyroid-stimulating hormone $\beta$ subunit mRNA expression in the rat pars tuberalis
}

\author{
Sayaka Aizawa, Takafumi Sakai and Ichiro Sakata \\ Area of Regulatory Biology, Division of Life Science, Graduate School of Science and Engineering, Saitama University, 255 Shimo-ohkubo, Sakuraku, Saitama \\ 338-8570, Japan \\ (Correspondence should be addressed to I Sakata; Email: isakata@mail.saitama-u.ac.jp)
}

\begin{abstract}
Thyroid-stimulating hormone (TSH)-producing cells of the pars tuberalis (PT) display distinct characteristics that differ from those of the pars distalis (PD). The mRNA expression of TSH $\beta$ and $\alpha G S U$ in PT has a circadian rhythm and is inhibited by melatonin via melatonin receptor type 1 ; however, the detailed regulatory mechanism for TSH $\beta$ expression in the PT remains unclear. To identify the factors that affect PT, a microarray analysis was performed on lasercaptured PT tissue to screen for genes coding for receptors that are abundantly expressed in the PT. In the PT, we found high expression of the $K A 2$, which is an ionotropic glutamic acid receptor (iGluR). In addition, the amino acid transporter A2 (ATA2), also known as the glutamine transporter, and glutaminase (GLS), as well as GLS2, were highly expressed in
\end{abstract}

the PT compared to the PD. We examined the effects of glutamine and glutamic acid on TSH $\beta$ expression and $\alpha$ GSU expression in PT slice cultures. L-Glutamine and L-glutamic acid significantly stimulated TSH $\beta$ expression in PT slices after 2- and 4-h treatments, and the effect of L-glutamic acid was stronger than that of L-glutamine. In contrast, treatment with glutamine and glutamic acid did not affect $\alpha G S U$ expression in the PT or the expression of TSH $\beta$ or $\alpha$ GSU in the PD. These results strongly suggest that glutamine is taken up by PT cells through ATA2 and that glutamic acid locally converted from glutamine by Gls induces TSH $\beta$ expression via the KA2 in an autocrine and/or paracrine manner in the PT.

Journal of Endocrinology (2012) 212, 383-394

\section{Introduction}

The pars tuberalis (PT), which comprises the rostral part of the anterior lobe of the pituitary gland that surrounds the median eminence as a thin cell layer, has characteristics different from those of the pars distalis (PD). The mammalian PT contains two cell types: hormone-producing cells and folliculo-stellate cells. In general, the hormone-producing cells in the PT are glycoprotein hormone cells, i.e. the thyroid-stimulating hormone (TSH) cells and gonado-tropic hormone cells (Rudolf et al. 1993). The hormone-producing cells in the PT vary according to species (Gross 1984). In rats, most of the hormone-producing cells in the PT are small and oval-shaped TSH-producing cells (Gross 1984) and they are characterized by spot-like TSH immunoreactivity on the Golgi apparatus (Sakai et al. 1992). TSH produced in the PT (PT-TSH) acts on the TSH receptors and regulates the expression of type 2 deiodinase (Dio2) in the ependymal cell layer of the mediobasal hypothalamus, which results in the regulation of $\mathrm{GnRH}$ release into the median eminence in seasonal animals (Yoshimura et al. 2003, Watanabe et al. 2004). This effect of PT-TSH has also been reported in mice, which are nonseasonal breeding animals (Ono et al. 2008).
The regulatory mechanisms of TSH $\beta$ and $\alpha$ GSU mRNA expression and TSH release in the thyrotropes of PT (PT-TSH cells) are believed to be different from those in PD cells because PT-TSH cells do not express the pituitary-specific transcription factor (Pit-1), TSH-releasing hormone receptor (TRH$\mathrm{R}$ ), and thyroid hormone receptor beta 2 (TR- $\beta 2$; Bockmann et al. 1997). In addition, a high density of melatonin-binding sites has been observed in the PT of many species (Williams \& Morgan 1988, Weaver et al. 1989), and melatonin receptor type 1 (MT1) is expressed within only $\alpha G S U$ - and $T S H \beta$ expressing cells in the rat PT (Klosen et al. 2002). Melatonin is exclusively secreted at night, and the duration of the melatonin signal corresponds to the duration of the dark period, thereby providing photoperiodic information to melatonin receptors (von Gall et al. 2002). This indicates that melatonin has physiological functions in the PT and that the PT might play an important role in the mediation of seasonal or circadian signals (Hazlerigg 2001). In fact, the duration of the photoperiod affects the structure of TSH cells and TSH $\beta$ mRNA expression in the PT cells of the Djungarian hamster (Bergmann et al. 1989, Bockmann et al. 1996, Arai \& Kameda 2004). We previously reported that expression of TSH $\beta$ and $\alpha G S U$ mRNA in the PT exhibits diurnal variations and that chronic 
administration of melatonin significantly suppresses $T S H \beta$ and $\alpha$ GSU mRNA expression (Aizawa et al. 2007). Moreover, we found that melatonin treatment alters TSH immunoreactivity and the number of TSH cells in the rat PT (Sakamoto et al. 2000). Another group also reported that acute melatonin injection suppresses TSH $\beta$ mRNA expression in the mouse PT (Unfried et al. 2009). Taken together, these findings suggest that TSH $\beta$ and $\alpha G S U$ mRNA expression in the PT is negatively regulated by melatonin.

Although PT-TSH is believed to play a physiologically important role as a photoperiodic mediator, the mechanisms by which PT-TSH is regulated remain unclear. Therefore, we performed a whole-genome expression analysis of lasercaptured rat PT tissue to screen for factors that might be involved in the regulation of PT-TSH. We found that the KA2 kinate receptor $(K A 2)$, which is an ionotropic glutamic acid receptor (iGluR; Herb et al. 1992, Hollmann \& Heinemann 1994); amino acid transporter A2 (ATA2), which is also known as the glutamine transporter (Sugawara et al. 2000); glutaminase (GLS); and GLS2 (de la Rosa et al. 2009) were highly expressed in the PT. Thus, we examined the effects of glutamic acid and glutamine on TSH $\beta$ and $\alpha$ GSU mRNA expression and TSH secretion in the PT.

\section{Materials and Methods}

\section{Animals}

Male Wistar rats weighing 200-250 g were maintained under

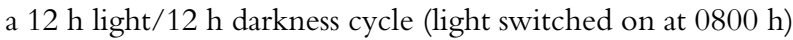
at room temperature $\left(23 \pm 2{ }^{\circ} \mathrm{C}\right)$ with food and water ad libitum. The animals were killed at Zeitgeber time 4 (ZT4) for tissue culture experiments and at ZT6 for microarray experiments. All procedures were approved and performed in accordance with the Saitama University Committee on Animal Research.

\section{Preparation of sections and laser microdissection}

Brains were frozen in Tissue-Tek OCT Compound (Sakura Finetek, Torrance, CA, USA) and stored at $-80^{\circ} \mathrm{C}$. Frozen, $20 \mu \mathrm{m}$ thick serial frontal sections were cut and mounted on membrane slides (cat. no. 11505189; Leica Microsystems, Wetzlar, Germany). To prevent RNA degradation during sectioning, these slides were precoated with $40 \mu \mathrm{l}$ RNAlaterICE (Ambion, Austin, TX, USA) and stored at $-20{ }^{\circ} \mathrm{C}$ inside a cryostat. The sections were fixed in ice-cold acetone for $2 \mathrm{~min}$, dehydrated with a graded ethanol series (75 and $50 \%$ ) for $1 \mathrm{~min}$ each, and stained for $10 \mathrm{~s}$ with $0 \cdot 1 \%$ Toluidine Blue (Sigma-Aldrich, St. Louis, MO, USA) dissolved in 50\% ethanol RNase-free water. The sections were rinsed in RNase-free water, dehydrated in a graded ethanol series (50 and $75 \%$ ) for $1 \mathrm{~min}$ each, immersed in 100\% ethanol for $5 \mathrm{~s}$, and dried using a cold-air dryer for $1 \mathrm{~min}$ in preparation for laser microdissection (LMD).

The PT, arcuate nucleus (Arc), and PD were dissected from stained sections using an LMD system (LMD 7000; Leica
Microsystems), and the cut sections were directly captured into $0.2 \mathrm{ml}$ tube caps filled with RLT buffer (RNeasy Micro Kit; Qiagen) containing $\beta$-mercaptoethanol (Supplementary Figure 1A, B and C; see section on supplementary data given at the end of this article). Total RNA was isolated using the RNeasy Micro Kit according to the manufacturer's protocol, including on-column DNase treatment. RNase-free water $(14 \mu \mathrm{l})$ was applied for elution. The integrity of the isolated total RNA was verified by high-resolution microcapillary electrophoresis using the RNA 6000 Pico LabChip and the Agilent 2100 Bioanalyzer (Agilent Technologies, Waldbronn, Germany). Agilent 2100 Bioanalyzer Software was used to analyze electropherograms and to quantify the $28 \mathrm{~S}$ and $18 \mathrm{~S}$ rRNA band intensities.

\section{Gene microarray analysis}

The total RNA (500 ng) from ten rats was pooled and used for the Oligo DNA microarray analysis using the 3D-Gene Rat Oligo chip 20k (Toray Industries, Tokyo, Japan). The total RNA was labeled with Cy5 using the Amino Allyl MessageAMP II aRNA Amplification Kit (Applied Biosystems, Foster City, CA, USA). Hybridization was performed according to the supplier's protocol (http://www.3d-gene. com). Hybridization signals were scanned using the ScanArray Express Scanner (PerkinElmer, San Jose, CA, USA) and processed using the GenePixPro version 5.0 (Molecular Devices, Sunnyvale, CA, USA). The raw data of each spot were normalized to the mean intensity of the background signal, which was determined according to the 95\% confidence intervals of all blank spot signal intensities. Raw signal intensities that were more than two S.D. higher than the background signal intensity were considered valid. The detected signals for each gene were normalized by a global normalization method (the median of the detected signal intensity was adjusted to 25 ).

\section{Brain slice preparation and slice culture}

Rats were killed at ZT4 when the TSH $\beta$ and $\alpha$ GSU mRNA expression in the rat PT reached its daily nadir (Aizawa et al. 2007). The brain was immediately removed and $600 \mu \mathrm{m}$ thick coronal slices were cut using a vibratome (VT1200S; Leica Microsystems) in ice-cold Dulbecco's PBS (-). These slices were then trimmed to $5 \times 5 \mathrm{~mm}$ that included the adjacent hypothalamic area of the PT. After preincubation in serumfree DMEM containing low glucose $(5.56 \mathrm{mM})$ without L-glutamine (cat. no. 11054-020; Invitrogen) for $2 \mathrm{~h}$, the medium was changed to DMEM containing low glucose with $1 \mathrm{mM}$ L-glutamic acid (Sigma-Aldrich) or $1 \mathrm{mM}$ L-glutamine (Sigma-Aldrich), and the incubation was continued for 2-8 h. The PD slices were cut to $1 \mathrm{~mm}$ thickness and incubated in the same manner. After incubation, slices were fixed with $4 \%$ paraformaldehyde (PFA) in $0.067 \mathrm{M}$ $\mathrm{PB}, \mathrm{pH} 7 \cdot 4$ containing $0 \cdot 02 \%$ glutaraldehyde for $12 \mathrm{~h}$ at $4{ }^{\circ} \mathrm{C}$. The slices were immersed in PBS containing 30\% sucrose for 
$20 \mathrm{~h}$ at $4{ }^{\circ} \mathrm{C}$ and frozen in Tissue-Tek Compound. Frozen, serial, $8 \mu \mathrm{m}$ thick frontal sections were cut and mounted on silane-coated slides for in situ hybridization (ISH). The incubated PD was immersed in Isogen (Nippon Gene, Tokyo, Japan) for quantitative PCR (qPCR).

\section{ISH for $m R N A$ s of TSH $\beta, \alpha G S U, M T 1$, and $K A 2$}

ISH was performed as described previously (Aizawa et al. 2007). Briefly, the sections were treated with $0.5 \mu \mathrm{g} / \mathrm{ml}$ proteinase $\mathrm{K}$ for $30 \mathrm{~min}$ at $37^{\circ} \mathrm{C}$, fixed with $4 \% \mathrm{PFA}$, and washed for $3 \mathrm{~min}$ with PBS. After treatment with $0.25 \%$ acetic anhydride in $0 \cdot 1 \mathrm{M}$ triethanolamine for $10 \mathrm{~min}$, the sections were washed with PBS for $1 \mathrm{~min}$. Digoxigenin (DIG)-labeled anti-sense and sense rat MT1 cRNA probes (GenBank accession no. NM_053676.1, position 1077-1485), rat KA2 cRNA probes (GenBank accession no. NM_031508.1, position 3123-3507), rat TSH $\beta$ cRNA probes (GenBank accession no. M10902, position 146-388), and rat $\alpha$ GSU cRNA probes (GenBank accession no. J00757, position 26-607) were synthesized using a labeling kit (Roche Diagnostics) with SP6 or T7 RNA polymerase (Roche Diagnostics). The probes were diluted to $1 \mathrm{ng} / \mu \mathrm{l}$ with hybridization buffer $(50 \%$ formamide, $3 \times$ saline sodium citrate (SSC; $150 \mathrm{mM} \mathrm{NaCl}, 15 \mathrm{mM}$ sodium citrate, $\mathrm{pH}$ 7.4), $0 \cdot 12 \mathrm{M} \mathrm{PB}, \mathrm{pH} 7 \cdot 4,1 \times$ Denhardt's solution, $125 \mu \mathrm{g} / \mathrm{ml}$ tRNA, $0 \cdot 1 \mathrm{mg} / \mathrm{ml}$ sonicated salmon sperm DNA, and $10 \%$ dextran sulfate) and placed on the tissue sections. A sense cRNA probe was used as a negative control. The sections were covered with Parafilm (Pechiney Plastic Packing Inc., Chicago, IL, USA) and incubated for $16 \mathrm{~h}$ at $58^{\circ} \mathrm{C}$ in a humidity chamber. The covers were removed by soaking the slides in $5 \times \mathrm{SSC}$, and the sections were subsequently immersed in $2 \times$ SSC containing $50 \%$ formamide for $30 \mathrm{~min}$. The sections were then treated with tris-NaCl-EDTA (TNE; $10 \mathrm{mM}$ Tris-HCl, $\mathrm{pH} 7 \cdot 6,500 \mathrm{mM} \mathrm{NaCl}$, and $1 \mathrm{mM} \mathrm{EDTA}, \mathrm{pH}$ 8.0) for $10 \mathrm{~min}$ and with RNase A ( $5 \mu \mathrm{g} / \mathrm{ml}$ in TNE) for $30 \mathrm{~min}$ at $37^{\circ} \mathrm{C}$. Next, the sections were immersed in TNE for $10 \min$ at $37^{\circ} \mathrm{C}$ and washed with $2 \times \mathrm{SSC}$ for $20 \mathrm{~min}$ at $50^{\circ} \mathrm{C}$ and $0.2 \times$ SSC for $20 \mathrm{~min}$, each twice at $50^{\circ} \mathrm{C}$. The sections were further incubated for $5 \mathrm{~min}$ in buffer-1 (100 mM Tris- $\mathrm{HCl}, 150 \mathrm{mM}$ $\mathrm{NaCl}$, and $0.01 \%$ Tween $20, \mathrm{pH} 7 \cdot 5$ ), immersed in $1.5 \%$ blocking reagent (Roche Diagnostics) in buffer-1 for $1 \mathrm{~h}$ at $37^{\circ} \mathrm{C}$, and subsequently washed in buffer- 1 for $5 \mathrm{~min}$. After washing, the sections were incubated with an alkaline phosphatase-conjugated anti-DIG antibody (Roche Diagnostics) diluted 1:1000 in buffer-1. The sections were washed in buffer-1 for $15 \mathrm{~min}$ twice and in buffer-2 $(100 \mathrm{mM}$ Tris- $\mathrm{HCl}$, $\mathrm{pH} 9 \cdot 5,100 \mathrm{mM} \mathrm{NaCl}$, and $50 \mathrm{mM} \mathrm{MgCl}_{2}$ ) for $3 \mathrm{~min}$. A chromagen solution $(337 \mu \mathrm{g} / \mathrm{ml}$ 4-nitroblue tetrazolium chloride and $175 \mu \mathrm{g} / \mathrm{ml}$ 5-bromo-4-chloro-3-indolyl-phosphate in buffer-2) was added, and the sections were incubated until a visible signal was detected. The reaction was stopped by adding a reaction stop solution $(10 \mathrm{mM}$ Tris $-\mathrm{HCl}, \mathrm{pH} 7 \cdot 6$ and 1 mM EDTA, pH 8.0). The sections were washed with PBS and covered with $90 \%$ glycerol in PBS.

\section{Immunohistochemistry for TSH}

The immunohistochemical detection of TSH using rabbit anti-rat TSH serum (HAC-RT29-01RBP86; a gift from the Laboratory of Biosignal Sciences, Institute for Molecular and Cellular Regulation, Gunma University) was performed using the avidin-biotin complex $(\mathrm{ABC})$ method. The production and specificity of the antibody have been described elsewhere (Kawarai 1980, Wakabayashi \& Tanaka 1988). The sections were treated with $0 \cdot 5 \%$ sodium metaperiodate to block endogenous peroxidase for $15 \mathrm{~min}$ at room temperature and were incubated with TNBS (1\% normal horse serum and $0 \cdot 4 \%$ Triton X-100 in PBS) for $1 \mathrm{~h}$. After washing with PBS, the sections were incubated overnight with anti-TSH serum diluted 1:40 000 in TNBS in a humidified chamber. The ABC method was used for immunohistochemistry (IHC) using a staining kit (Vectastain ABC kit, Vector, Burlingame, CA, USA). All incubations were performed in a humidified chamber at room temperature. The reactions were visualized with $0.02 \% 3^{\prime} 3$-diaminobenzidine tetrachloride in $0.006 \%$ $\mathrm{H}_{2} \mathrm{O}_{2}$ in $50 \mathrm{mM}$ Tris- $\mathrm{HCl}$, pH 7·6.

\section{$R N A$ extraction and $q P C R$}

The total RNA from the LMD-captured PT, Arc, and PD was extracted using the LMD and RNeasy Micro Kit mentioned above. The total RNA from the cultured PD was extracted using an Isogen Kit according to the manufacturer's instructions. The cDNA was synthesized from $60 \mathrm{ng}$ total RNA from the LMD-captured tissues using the High Capacity RNA-to-cDNA kit (Applied Biosystems). The cDNA of the cultured PD was synthesized from $1 \mu \mathrm{g}$ DNase-treated total RNA with random primers using ReverTra Ace (Toyobo, Osaka, Japan). The primers used in this study are summarized in Supplementary Table 1, see section on supplementary data given at the end of this article. The qPCR reactions were performed using a LightCycler (Roche Diagnostics) with SYBR Premix Ex Taq (TakaraBio, Shiga, Japan). The initial template denaturation was programmed for $30 \mathrm{~s}$ at $95^{\circ} \mathrm{C}$. PCR was performed with 40 cycles of $5 \mathrm{~s}$ at $95^{\circ} \mathrm{C}$ and $15 \mathrm{~s}$ at $60{ }^{\circ} \mathrm{C}$, and a final cooling step was performed for $30 \mathrm{~s}$ at $40^{\circ} \mathrm{C}$. Rat GAPDH mRNA was used as the invariant control. The expression of each mRNA is shown relative to GAPDH mRNA expression. All reactions were performed in duplicate, and each transcript was quantitatively measured by establishing a linear amplification curve from serial dilutions of each plasmid containing the amplicon sequence. The amplicon size and specificity were confirmed by a melting curve analysis and $2 \%$ agarose gel electrophoresis.

\section{In vitro TSH secretion from $P T$ and $P D$}

Brain slices were prepared using the same method as described above. Coronal slices $(600 \mu \mathrm{m}$ thick) were trimmed to $4 \times$ $2 \mathrm{~mm}$ squares that included the adjacent median eminence with the PT. Three slices of the PT from one brain were 
Table 1 Candidate high-expressing genes in pars tuberalis (PT)

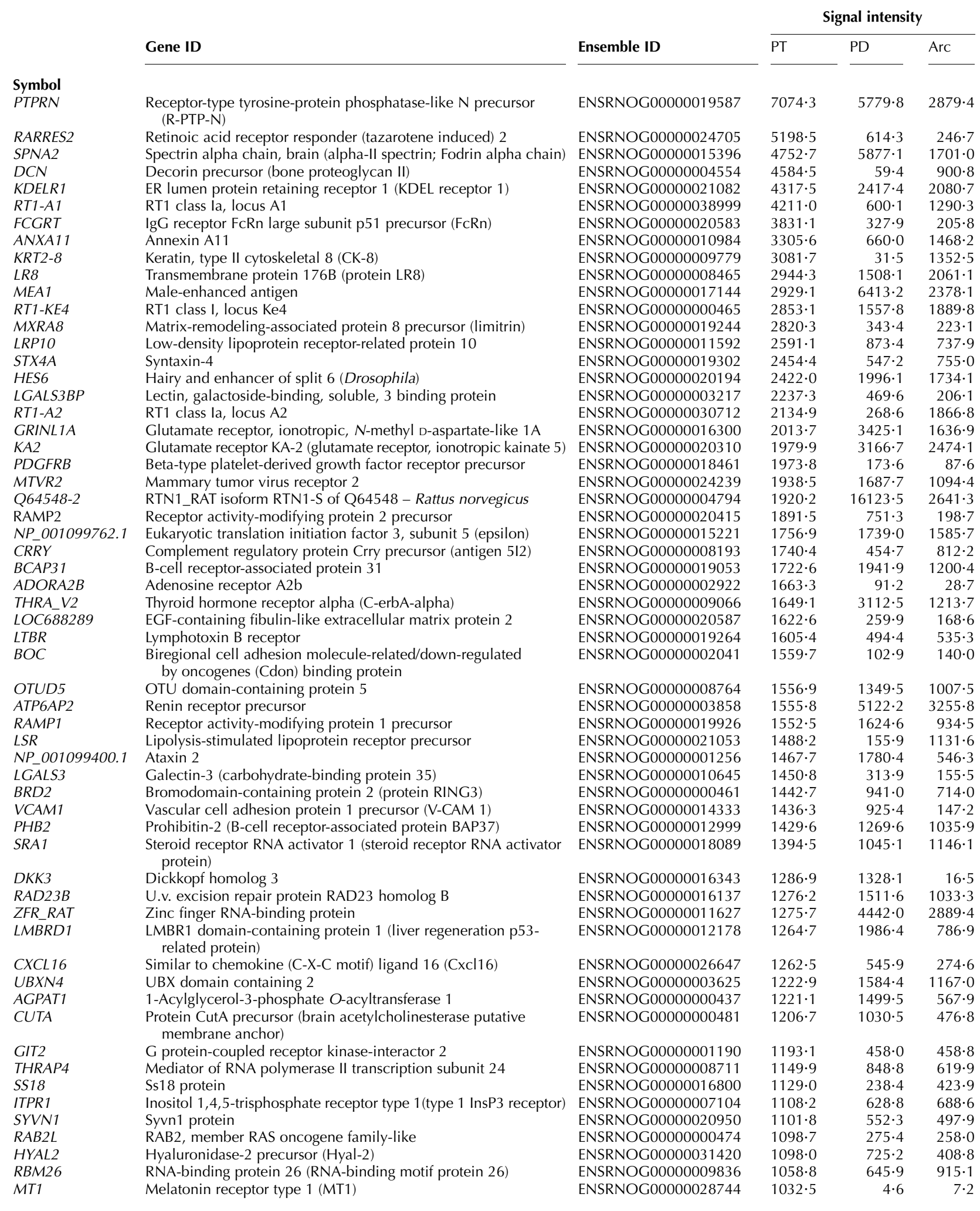



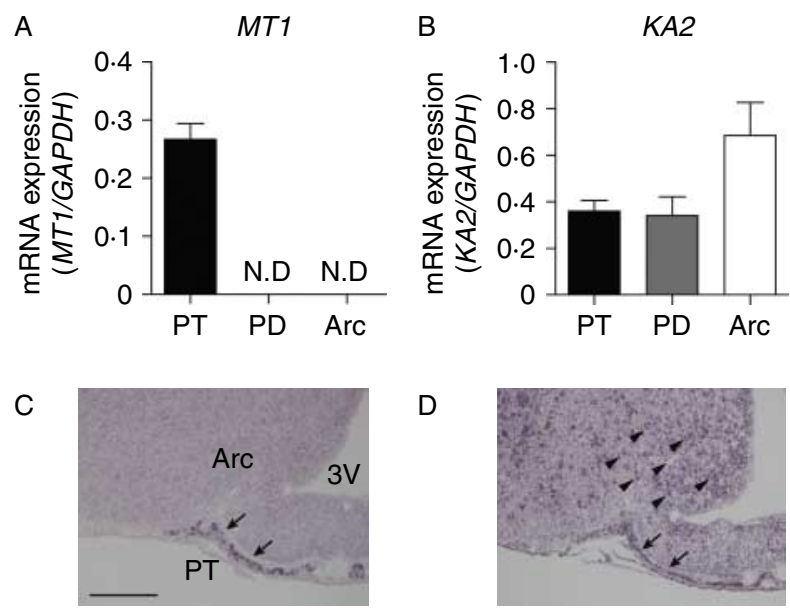

D

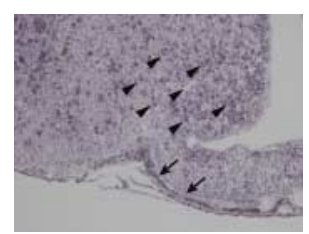

Figure 1 MT1 and KA2 mRNA expression in the PT, PD, and Arc of male Wistar rats. (A) qPCR for MT1 in the PT, PD, and Arc using LMD samples. High MT1 expression was detected only in the PT. All values are means \pm S.E.M. $(n=3)$. (B) $K A 2$ mRNA expression in the PT, PD, and Arc. The KA2 mRNA level in the PT was similar to that in the PD. Although there was no statistically significant difference in its mRNA levels between the PT and Arc, the KA2 mRNA level tended to be lower in the PT $(P=0 \cdot 057)$. All values are means \pm s.E.M. $(n=3)$. (C) Microphotograph of MT1 mRNAexpressing cells detected by ISH. MT1 mRNA-expressing cells were restricted to the PT (arrows). (D) Microphotograph of KA2 mRNAexpressing cells detected by ISH. KA2 mRNA-expressing cells were observed not only in the PT (arrows) but also in the hypothalamus, including the Arc (arrowheads). Scale bar: $200 \mu \mathrm{m}$. PT, pars tuberalis; Arc, arcuate nucleus; and $3 \mathrm{~V}$, third ventricle. Full color version of this figure available via http://dx.doi.org/10.1530/JOE11-0388.

incubated in $50 \mu \mathrm{l}$ culture medium (serum-free DMEM containing low glucose without L-glutamine, cat. No. 11054020; Invitrogen) using a noncoated 96 well plate. The PD slices were also cut into a thickness of $1 \mathrm{~mm}$ and incubated in $200 \mu \mathrm{l}$ culture medium using a noncoated 48 well plate. After preincubation for $2 \mathrm{~h}$, the brain slices were incubated in culture medium with $1 \mathrm{mM}$ L-glutamine (Sigma-Aldrich) or $1 \mathrm{mM}$ L-glutamic acid (Sigma-Aldrich) for $4 \mathrm{~h}$. As a control, L-glutamine-free and L-glutamic acid-free culture media were both used. The media were subsequently centrifuged at $1000 \mathrm{~g}$ for $5 \mathrm{~min}$, and the supernatants were collected and stored at $-80^{\circ} \mathrm{C}$ until analysis. The TSH concentrations in the media were measured using an Lbis Rat TSH ELISA Kit (code no. AKRTS-010R; Shibayagi, Gunma, Japan) according to the manufacturer's instructions.

\section{Morphological analysis}

Sections stained for ISH and IHC were observed under a light microscope (BX60; Olympus, Tokyo, Japan) and photographed with a digital camera (DP70; Olympus). The digital images were transformed into gray scale by Adobe Photoshop (Adobe Systems), and a statistical analysis was carried out for the mean density per pixel measured using Scion Image (Scion, Frederick, MD, USA).

\section{Statistical analysis}

The values are given as the means \pm s.E.M. Differences among groups were evaluated by a one-way ANOVA with Tukey's post-hoc tests using GraphPad Prism 5 Software (GraphPad Software, La Jolla, CA, USA). Differences with $P<0.05$ were considered significant.
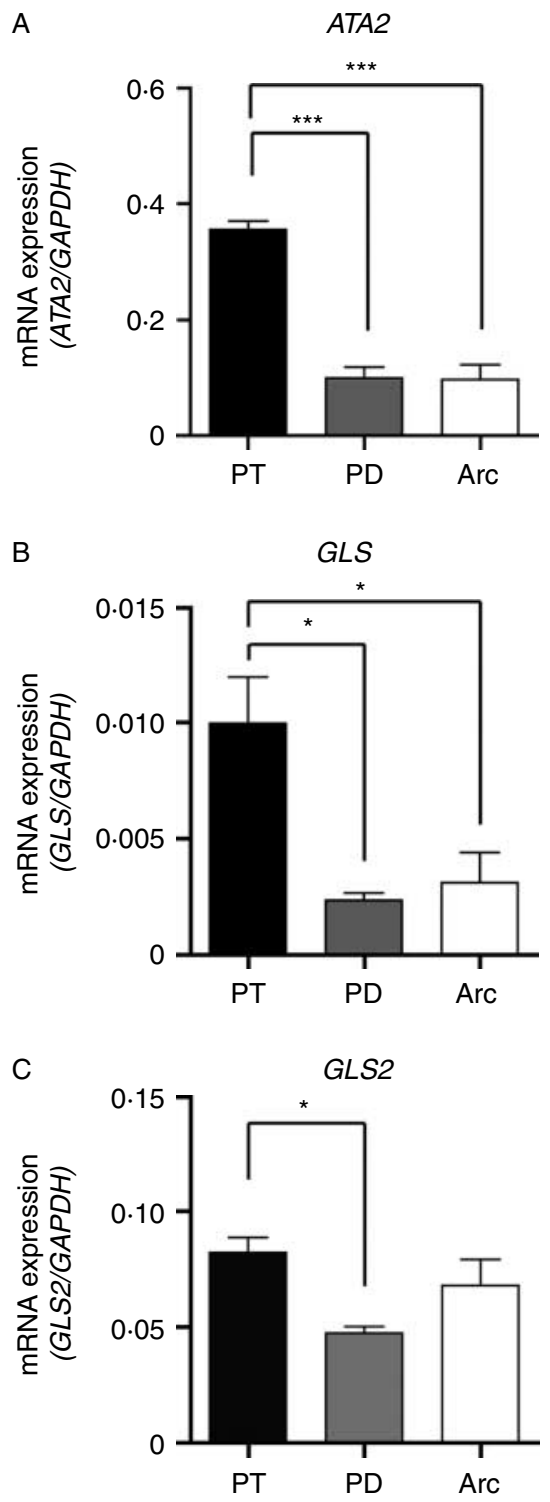

Figure 2 QPCR analysis of glutamic acid signaling components in the PT, PD, and Arc. (A) Glutamine transporter ATA2 mRNA expression in the PT, PD, and Arc. The ATA2 mRNA level was significantly higher in the PT than in the PD and Arc. (B) GLS mRNA expression in the PT, PD, and Arc. GLS mRNA expression was higher in the PT than in the PD and Arc. (C) GLS2 mRNA expression in the PT, PD, and Arc. GLS2 mRNA expression in the PT was significantly higher than that in the PD but comparable to that in the Arc. Values are the means \pm s.E.M. $(n=3) .{ }^{*} P<0.05$ and $* * * P<0 \cdot 001$. 


\section{Results}

iGluR KA2 expression in the PT

To identify candidate genes in this microarray study using the dataset of molecular functions for Gene Ontology (http:// www.geneontology.org/), we screened for genes that had 'receptor activity'. According to our results, 59 genes exhibiting higher expression levels than MT1 (microarray signal intensity: 1032.5) were identified as candidate receptor genes with high expression in PT (Table 1). The adenosine receptor $A 2 B$ gene, which is expressed in the PT (Rivkees \& Reppert 1992, Stehle et al. 1992), was found among these genes (microarray signal intensity: 1663.3; Table 1). The expression of the $M T 1$ and adenosine receptor $A 2 B$ genes was restricted in the PT, and their expression in the PD and Arc was notably low, i.e. not detected using this chip. Using this dataset, we first found that the expression of the $K A 2$ was high in the PT. The expression of KA2 (microarray signal intensity: 1979.9) was higher than that of MT1 and the adenosine receptor $A 2 B$ (Table 1). In contrast, a high signal intensity for the $K A 2$ was detected not only in PT but also in PD (microarray signal intensity: 2474-1) and Arc (microarray signal intensity: $3166 \cdot 7$; Table 1).

For this study, qPCR and ISH were performed for MT1 and $K A 2$ to validate the dataset obtained by the microarray analysis (Fig. 1). MT1 expression was only detected in the PT (Fig. 1A), and the expression of the KA2 in the PT and PD was similar and tended to be lower than that in the Arc (Fig. 1B). MT1 mRNA-expressing cells were observed only in the PT, whereas KA2 mRNA-expressing cells were observed in the PT and the entire hypothalamus, including the Arc (Fig. 1C and D). A sense RNA probe to either the $M T 1$ or $K A 2$ generated no specific signal (data not shown). In addition, the microarray data showed that the expression of the other iGluRs and metabotropic GluRs (mGluRs) was low in the PT and that the NMDA receptor NR2C, KA1 receptor, AMPA receptor GLUR2, and MGLUR1 were expressed highly in the Arc. GLUR2 and KA2 expression was also detected in the PD (data not shown).

\section{Glutamic acid signaling molecules in the PT}

Glutamic acid is locally synthesized from glutamine and acts on GluRs as an autocrine and/or paracrine extracellular signal mediator in the central nervous system (CNS) and peripheral tissues. To determine whether glutamic acid synthesis occurs in the PT, we analyzed the expression of the molecules involved in glutamic acid synthesis, i.e. the glutamine transporter and Gls. In the microarray dataset, ATA2, which is a glutamine transporter, was detected in the PT (data not shown). The expression of $A T A 2$ (microarray signal intensity: 2460.6) was much higher in the PT than in the PD (microarray signal intensity: 539.5) and Arc (microarray signal intensity: 625.2). Moreover, qPCR revealed that the
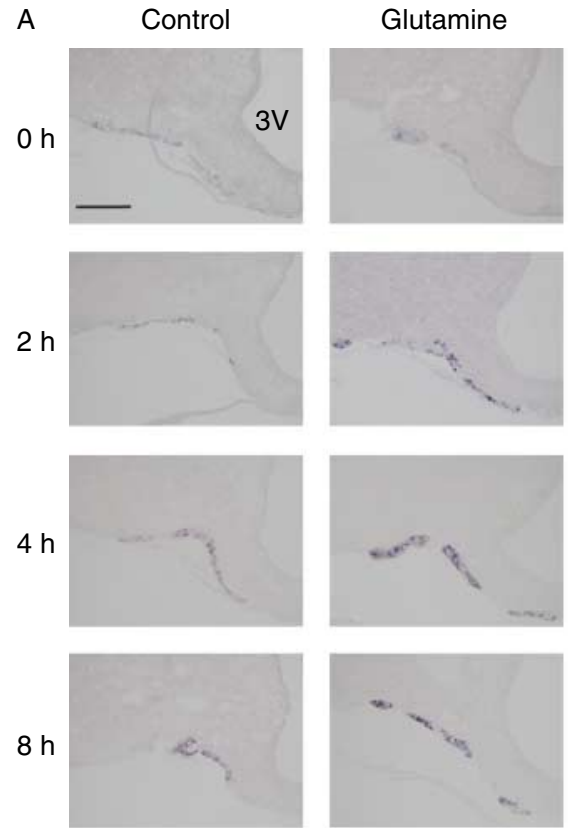

B
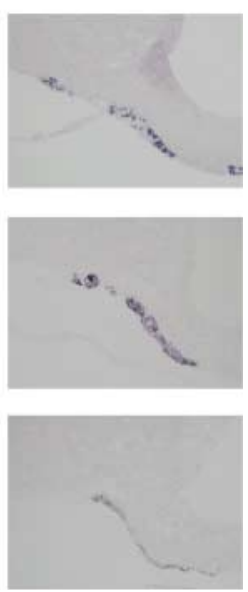

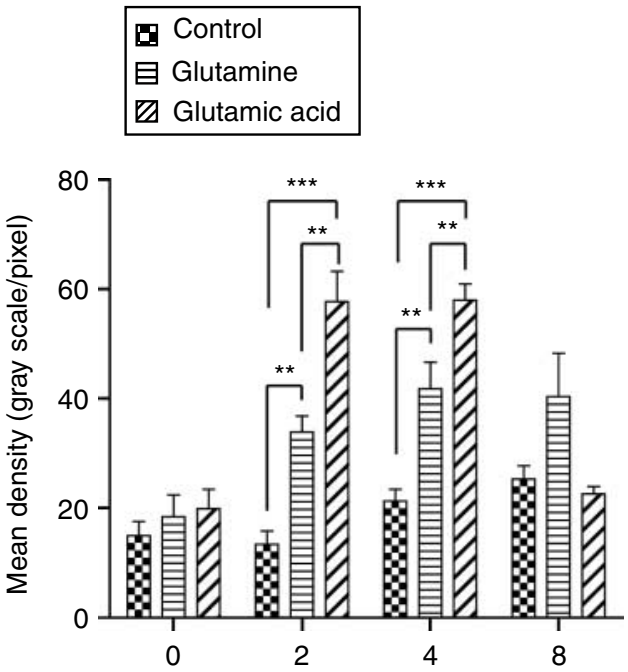

(h)

Figure 3 Effects of glutamine and glutamic acid on TSH $\beta$ mRNA expression in the PT, as determined by ISH. (A) Microphotographs of ISH for $T S H \beta$ mRNA. The staining densities of TSH $\beta$ mRNA were altered by treatment with glutamine (middle column) or glutamic acid (right column) compared to the control (left column) at each time point. Scale bar $=200 \mu \mathrm{m}$. $3 \mathrm{~V}$, third ventricle. (B) Morphometric analysis showing that treatment with glutamine or glutamic acid significantly increased TSH $\beta$ mRNA expression compared to the control at 2 and 4 h. The effect of glutamic acid on TSH $\beta$ mRNA expression was significantly stronger than that of glutamine at 2 and $4 \mathrm{~h}$. Values are the means \pm S.E.M. $(n=4)$. ${ }^{* *} P<0 \cdot 01$ and ${ }^{* * *} P<0 \cdot 001$. Full color version of this figure available via http://dx.doi.org/10.1530/JOE-11-0388. 
expression of $A T A 2$ was significantly higher in the $\mathrm{PT}$ than in the PD and Arc $(P<0 \cdot 001$; Fig. 2A). In addition, the expression of GLS and GLS2 was also detected in the PT, and the expression of GLS was higher in the PT than in the PD and $\operatorname{Arc}(P<0 \cdot 05$; Fig. 2B). GLS2 expression was significantly higher in the PT than in the PD but was comparable to that in $\operatorname{Arc}(P<0 \cdot 05$, PT vs PD; Fig. 2C).

\section{Effects of glutamine and glutamic acid on PT-TSH}

To determine the effect of glutamine or glutamic acid on the expression of TSH $\beta$ and $\alpha G S U$ mRNA in the PT, slice culture experiments were performed (Figs 3 and 4). In the control, the signal density of ISH for TSH $\beta$ mRNA was low at $0 \mathrm{~h}$ and increased slightly at $8 \mathrm{~h}$ (Fig. 3A, left column). In contrast, treatment with glutamine increased the staining density in a time-dependent manner, and strong staining was detected at 4 and $8 \mathrm{~h}$ (Fig. 3A, middle column). Moreover, glutamic acid treatment strongly intensified the staining density at 2 and $4 \mathrm{~h}$; however, the staining density decreased at $8 \mathrm{~h}$ (Fig. 3A, right column). A statistical analysis of the images showed that glutamine and glutamic acid significantly increased the TSH $\beta$ mRNA expression compared to the control at 2 and $4 \mathrm{~h}$ (Fig. 3B). Moreover, the TSH $\beta$ mRNA expression at 2 and $4 \mathrm{~h}$ after glutamic acid treatment was significantly higher than those after glutamine treatment $(P<0.01$; Fig. 3B). In contrast, neither glutamine nor glutamic acid stimulated the expression of $\alpha$ GSU in the PT (Fig. 4A and B). The TSH immunoreactivity in the PT was not affected by the addition of glutamine or glutamic acid to the medium (Fig. 5), and spot-like staining of the Golgi apparatus was observed in all examined conditions (Fig. 5A). However, after $8 \mathrm{~h}$ of incubation with glutamic acid, strong spot-like staining of the Golgi apparatus was observed, which was consistent with the control, but weak cytoplasmic staining was also observed (Fig. 5A, right bottom); this staining density was significantly lower than that of the control $(P<0 \cdot 01)$ and glutamine-treated samples $(P<0 \cdot 05$; Fig. 5B). Additionally, to analyze the TSH secretion from the PT, we performed an in vitro slice culture of the PT. Treatment with $1 \mathrm{mM}$ glutamic acid significantly increased the TSH concentration in the medium compared to the control $(P<0 \cdot 05$; Fig. 5C). Although the difference was not statistically significant, glutamine treatment tended to increase the TSH concentration (Fig. 5C). Additionally, after treatment with glutamic acid or glutamine for $4 \mathrm{~h}$, we treated the slices with $50 \mathrm{mM} \mathrm{KCl}$ to release the stored TSH in the cells. $\mathrm{KCl}$ treatment for $2 \mathrm{~h}$ did not induce TSH secretion (data not shown).

\section{Effects of glutamine and glutamic acid on PD-TSH}

Finally, we examined the effect of treatment with glutamic acid or glutamine on TSH $\beta$ and $\alpha$ GSU expression in the
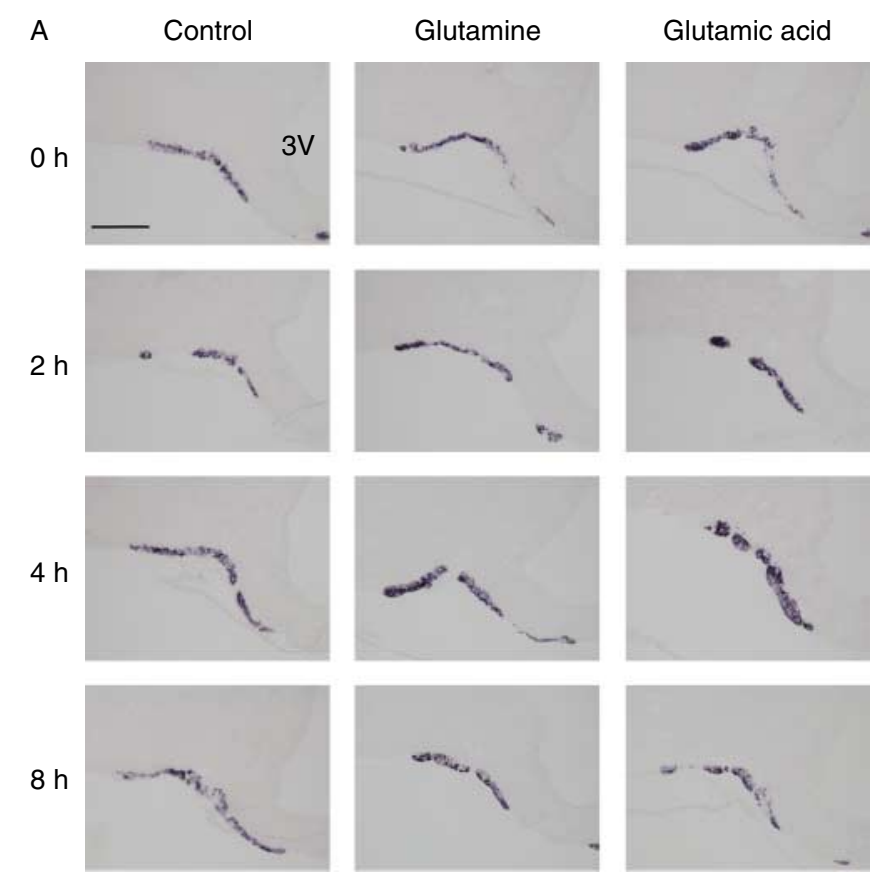

B

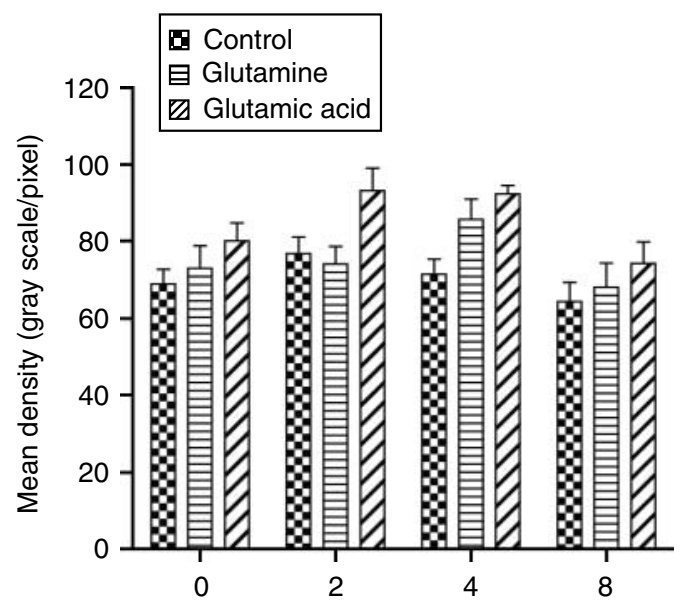

(h)

Figure 4 Effects of glutamine and glutamic acid on $\alpha G S U$ mRNA expression in the PT, as determined by ISH. (A) Microphotographs of ISH for $\alpha G S U$ mRNA. The staining density of $\alpha G S U$ mRNA was not changed by treatment with glutamine (middle column) or glutamic acid (right column) compared to the control (left column) at each time point. Scale bar $=200 \mu \mathrm{m}$. 3V, third ventricle. (B) Morphometric analysis showing that treatment with glutamic acid or glutamine did not affect the staining density of $\alpha G S U$ in PT. Values are the means \pm s.E.M. $(n=4)$. Full color version of this figure available via http://dx.doi.org/10.1530/JOE-11-0388. 
A
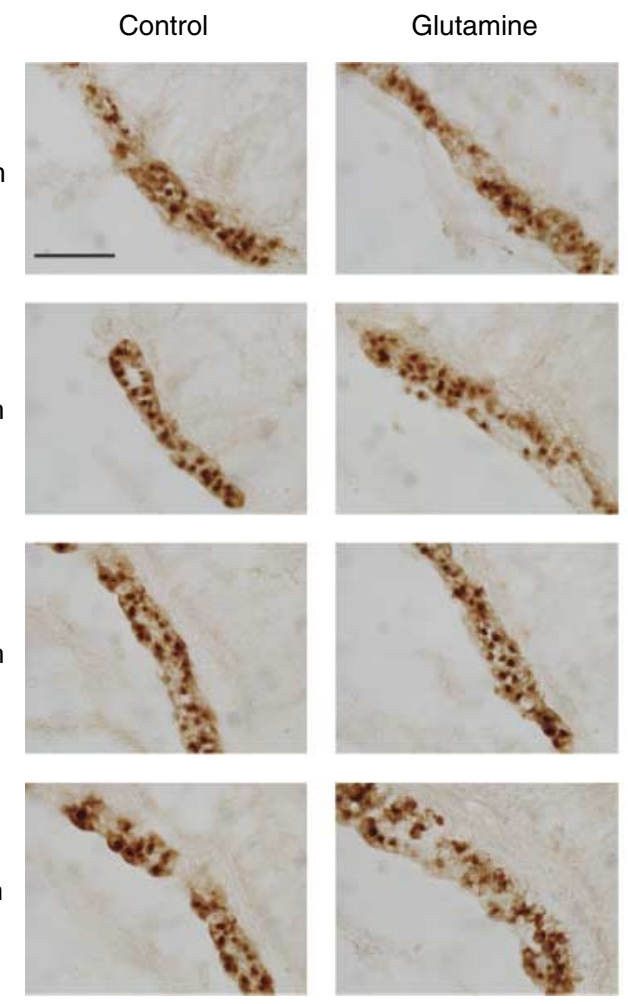

Glutamic acid
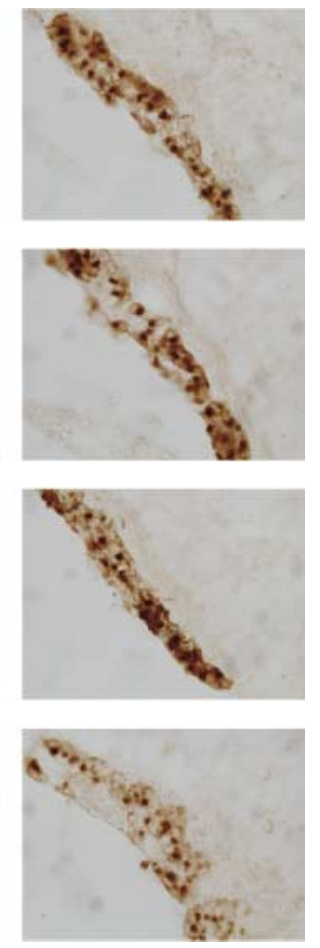
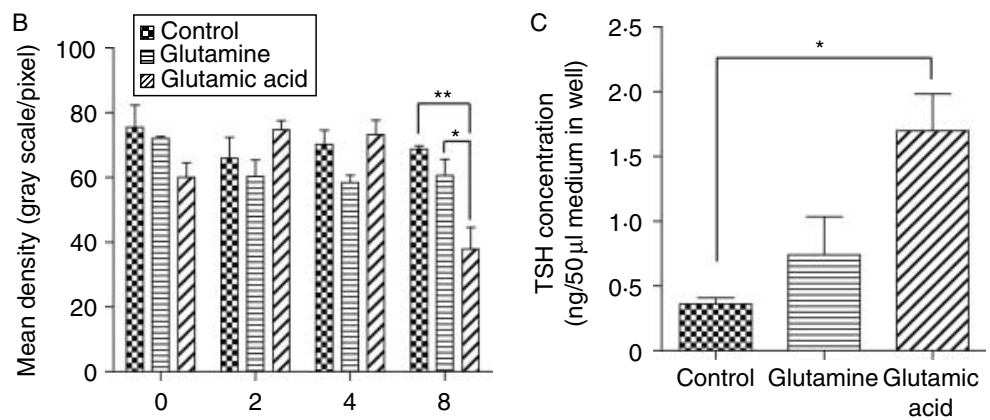

(h)

Figure 5 Effects of glutamine and glutamic acid on TSH immunoreactivity and TSH secretion in the PT. (A) Microphotographs of TSH immunoreactivity determined by IHC. Strong spot-like staining of the Golgi apparatus was observed in all examined conditions. Strong spot-like staining of the Golgi apparatus was observed, consistent with that in the control, but weak cytoplasmic staining was observed $8 \mathrm{~h}$ after glutamic acid treatment. Scale bar $=50 \mu \mathrm{m}$. 3V, third ventricle. (B) Morphometric analysis showed that the staining density was not altered at 0,2 , or $4 \mathrm{~h}$ after glutamine or glutamic acid treatment. After incubation with glutamic acid for $8 \mathrm{~h}$, the TSH immunoreactivity in PT was significantly lower than that in the control or after glutamine treatment. ${ }^{*} P<0 \cdot 05$ and $* * P<0 \cdot 01$. Values are the means \pm s.E.M. $(n=4)$. (C) ELISA measuring the concentration of TSH secreted into the medium from brain slices that included the PT. Treatment with $1 \mathrm{mM}$ glutamic acid for $4 \mathrm{~h}$ significantly increased the TSH secretion compared to the control. $* P<0 \cdot 05$. Values are the means \pm s.E.M. $(n=3)$. Full color version of this figure available via http://dx.doi.org/10.1530/JOE-11-0388.

cultured PD by qPCR. No significant difference was observed in TSH $\beta$ or $\alpha$ GSU expression in the PD (Fig. 6A and $\mathrm{B})$. In addition, neither glutamine nor glutamic acid altered TSH secretion into the medium (Fig. 6C). However, $50 \mathrm{mM} \mathrm{KCl}$ stimulation significantly increased the TSH concentration (data not shown).

\section{Discussion}

TSH $\beta$ and $\alpha G S U$ expression and TSH secretion have been thoroughly studied in the PD and are regulated by the TRHTSH-thyroid hormone feedback loop (Shupnik \& Ridgway 1985, Carr et al. 1989, Zoeller et al. 2007). In addition, 


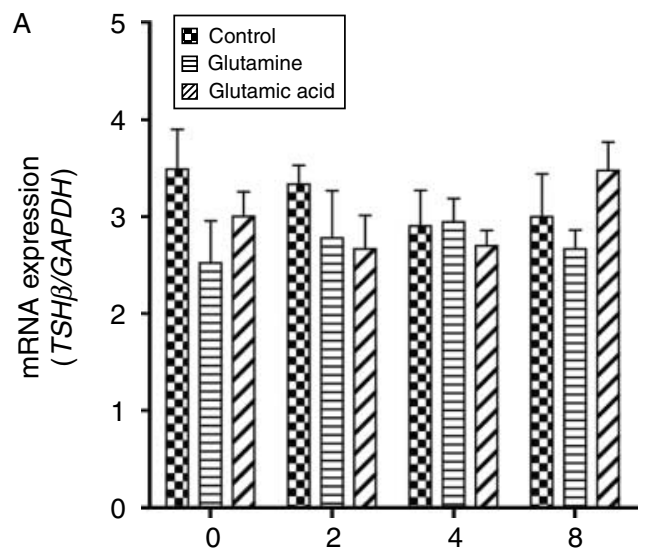

(h)

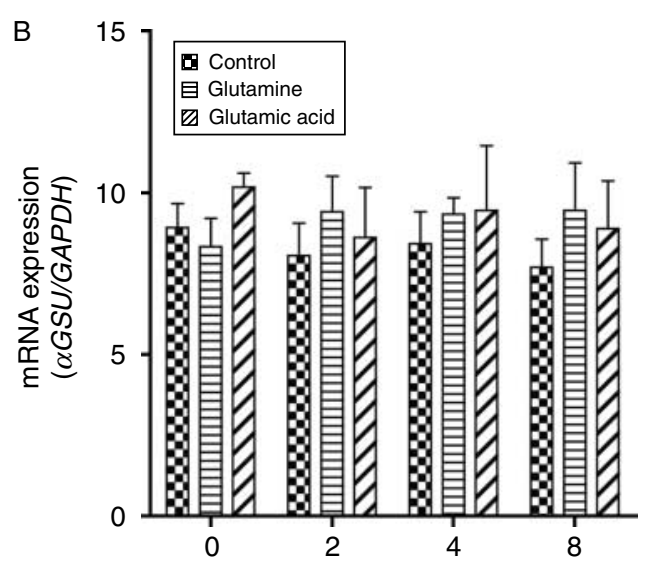

(h)

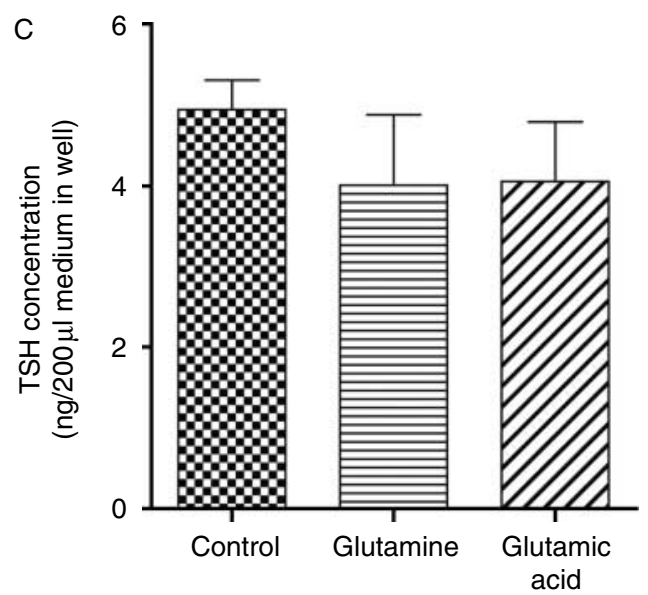

Figure 6 Effect of glutamine and glutamic acid on PD-TSH mRNA expression and PD-TSH secretion. (A) $T S H \beta$ mRNA expression and (B) $\alpha G S U$ mRNA expression determined by qPCR were not altered by either treatment at either time point. The values are the means \pm S.E.M. $(n=3)$. (C) The TSH secretion in the PD was determined by ELISA. The TSH secretion was also not affected by each treatment. The values are the means \pm S.E.M. $(n=3)$. vasopressin, somatostatin, and dopamine are involved in the regulation of TSH $\beta$ and $\alpha$ GSU expression and TSH secretion in the PD through specific receptors (Krass et al. 1968, Samuels et al. 1992, Lam \& Wong 1999). However, the regulatory mechanisms for TSH expression and secretion in the PT are believed to be different from those in the PD because TRH-R and TR- $\beta 2$ are not produced in PT-TSH cells (Bockmann et al. 1997), and the mRNAs of the receptors for vasopressin, somatostatin, and dopamine were not detected in the PT in our microarray analysis or by $\mathrm{qPCR}$ (data not shown). In fact, TSH $\beta$ and $\alpha G S U$ mRNA expression exhibits diurnal variations, and the chronic administration of melatonin significantly suppresses TSH $\beta$ and $\alpha$ GSU mRNA expression in the PT (Aizawa et al. 2007). The $5^{\prime}$-upstream region of the TSH $\beta$ gene, including an E-box-like element and cAMP response-like element, can be upregulated by the clock proteins BMAL1 and CLOCK, which are expressed in the PT (Unfried et al. 2009). In addition, Eya3, which is a transcription factor expressed in the PT, and Six1 synergistically induce TSH $\beta$ expression via the six consensus sequence, and the activation of the TSH $\beta$ promoter is further enhanced by Tef and Hlf via the D-box (Masumoto et al. 2010). Thus, it has been suggested that these transcriptional factors, which are rhythmically expressed in the PT, regulate PT-TSH $\beta$ mRNA expression.

In this study, we found that glutamic acid stimulates $T S H \beta$ mRNA expression in the PT. Glutamic acid plays an important role not only as an excitatory amino acid neurotransmitter in the CNS but also as an extracellular signal mediator in peripheral tissues, including the PD (Hinoi et al. 2004). Specific, high-affinity binding sites for $\left[{ }^{3} \mathrm{H}\right]$ glutamic acid are located in the pituitary gland and brain of the rat (Yoneda \& Ogita 1986, Meeker et al. 1994). Molecular biological and immunohistochemical analyses have demonstrated the presence of non-NMDA (Kiyama et al. 1993, Mahesh et al. 1999) and NMDA iGluRs in the pituitary gland (Petralia et al. 1994, Bhat et al. 1995). In addition, Hinoi et al. demonstrated that $\left[{ }^{3} \mathrm{H}\right]$ kinate (KA), which is an agonist of KA receptors, binds to the rat pituitary gland. Hinoi et al. also showed that an i.p. injection of KA increases the DNAbinding activity of the nuclear transcription factor activator protein-1 (AP1) in the rat pituitary gland and hippocampus (Hinoi \& Yoneda 2001). In isolated rat pituitary melanotropes, glutamic acid induces a marked increase in the cytosolic free $\mathrm{Ca}^{2+}$ concentration by a nonsynaptic mechanism (Giovannucci \& Stuenkel 1995). Collectively, these findings indicate that particular subtypes of GluRs are functionally expressed in the pituitary gland. Several studies have demonstrated the direct regulation of hormone secretion by glutamic acid in primary anterior pituitary cells, e.g. the secretion of prolactin is induced by $1 \mathrm{mM}$ glutamic acid (Pampillo et al. 2002), and its effect is blocked by MK-801, which is an antagonist of NMDA iGluRs (Login 1990). NMDA, which is an agonist of NMDA receptors, and KA both induce the secretion of GH (Niimi et al. 1994), and KA 
stimulates LH and FSH release from the anterior pituitary gland (Zanisi et al. 1994).

Although many studies have demonstrated the physiological effect of glutamic acid on the PD, the effects of glutamic acid on the PT, including the expression of GluRs and the synthesis pathway of glutamic acid, have not yet been established. In this study, we showed that the mRNA expression of the iGluR KA2 in the PT was higher than that of MT1 (Williams \& Morgan 1988, Weaver et al. 1989) and the adenosine receptor $A 2 B$ (Rivkees \& Reppert 1992, Stehle et al. 1992). Our microarray analysis showed that among GluRs, only KA2 was expressed in the PT. Moreover, our slice culture experiment indicated that glutamic acid significantly enhanced TSH $\beta$ mRNA expression at 2 and $4 \mathrm{~h}$, whereas glutamic acid did not alter the expression of $\alpha \mathrm{GSU}$ mRNA in the PT or the expression of TSH $\beta$ or $\alpha$ GSU in the PD. Taken together, these results suggest that the regulatory mechanisms of TSH $\beta$ mRNA expression are different in the PT and PD, and that glutamic acid is necessary for the maintenance of TSH $\beta$ expression in the PT. Although glutamic acid significantly induced TSH $\beta$ mRNA expression, we did not observe any corresponding staining differences in TSH immunoreactivity. However, the TSH secretion from the PT was significantly increased by the glutamic acid treatment, and this finding was consistent with the observed TSH $\beta$ mRNA expression level. Most of the hormoneproducing cells in the rat PT are small and oval-shaped TSH-producing cells (Gross 1984) and are characterized by spot-like TSH immunoreactivity on the Golgi apparatus, with few secretory granules being found in the cytoplasm under electron microscopic observation (Sakai et al. 1992), which suggests that TSH may be secreted constitutively from PT-TSH cells. In this study, spot-like TSH-immunoreactive staining of the Golgi apparatus was observed in all examined conditions (Fig. 5A). Furthermore, $\mathrm{KCl}$ treatment of the PT slice cultures did not stimulate the secretion of TSH into the medium (data not shown). Taken together, these results suggest that glutamic acid induces TSH $\beta$ mRNA transcription and increases TSH production, and that TSH is immediately and constitutively secreted without accumulating in the cells.

Most glutamic acid obtained from food is consumed by the gut as the metabolic fuel, and little glutamic acid enters the blood stream (Reeds et al. 1996, 2000). The circulating glutamic acid concentration is low $(0.07-0.1 \mathrm{mM}$ in the plasma; Hawkins et al. 1995, Wang et al. 2007), which indicates that circulating glutamic acid does not physiologically interact with GluRs. In general, glutamic acid is locally converted by Gls from glutamine, which is absorbed into the cell via glutamine transporters (de la Rosa et al. 2009), acts as an autocrine and/or paracrine neurotransmitter in the CNS, and functions as an extracellular signal mediator in the peripheral tissues (Hinoi et al. 2004). The plasma concentration of glutamine generally ranges from 0.5 to $1.0 \mathrm{mM}$ and may change in certain physiological states (Wang et al. 2007). Therefore, the $1 \mathrm{mM}$ concentrations of glutamine used in this study are reasonable and reflect the physiological conditions in vivo. We demonstrated that the ATA2 expression in the PT was much higher than that in the PD and Arc. In addition, GLS and GLS2 were expressed in the PT, and glutamine induced a time-dependent increase in TSH $\beta$ mRNA expression in the PT. These results indicate that the glutamic acid synthesis pathway is active in the PT and that glutamic acid that is locally converted from glutamine in the PT stimulates TSH $\beta$ expression in an autocrine and/or paracrine manner.

\section{Supplementary data}

This is linked to the online version of the paper at http://dx.doi.org/10.1530/ JOE-11-0388.

\section{Declaration of interest}

The authors declare that there is no conflict of interest that could be perceived as prejudicing the impartiality of the research reported.

\section{Funding}

This research did not receive any specific grant from any funding agency in the public, commercial or not-for-profit sector.

\section{Acknowledgements}

We thank Dr Shinji Tsukahara for his helpful assistance with LMD and Ms Moemi Kishimoto and Ms Mai Nagasaka for their technical assistance.

\section{References}

Aizawa S, Hoshino S, Sakata I, Adachi A, Yashima S, Hattori A \& Sakai T 2007 Diurnal change of thyroid-stimulating hormone mRNA expression in the rat pars tuberalis. Journal of Neuroendocrinology 19 839-846. (doi:10. 1111/j.1365-2826.2007.01603.x)

Arai Y \& Kameda Y 2004 Diurnal rhythms of common alpha-subunit mRNA expression in the pars tuberalis of hamsters and chickens. Cell and Tissue Research 317 279-288. (doi:10.1007/s00441-004-0912-8)

Bergmann M, Wittkowski W \& Hoffmann K 1989 Ultrastructural localization of thyrotropin (TSH)-like immunoreactivity in specific secretory cells of the hypophyseal pars tuberalis in the Djungarian hamster, Phodopus sungorus. Cell and Tissue Research 256 649-652.

Bhat GK, Mahesh VB, Chu ZW, Chorich LP, Zamorano PL \& Brann DW 1995 Localization of the $N$-methyl-D-aspartate R1 receptor subunit in specific anterior pituitary hormone cell types of the female rat. Neuroendocrinology 62 178-186. (doi:10.1159/000127003)

Bockmann J, Bockers TM, Vennemann B, Niklowitz P, Muller J, Wittkowski W, Sabel B \& Kreutz MR 1996 Short photoperiod-dependent downregulation of thyrotropin-alpha and -beta in hamster pars tuberalis-specific cells is prevented by pinealectomy. Endocrinology 137 1804-1813. (doi:10. 1210/en.137.5.1804)

Bockmann J, Bockers TM, Winter C, Wittkowski W, Winterhoff H, Deufel T \& Kreutz MR 1997 Thyrotropin expression in hypophyseal pars tuberalisspecific cells is $3,5,3^{\prime}$-triiodothyronine, thyrotropin-releasing hormone, and pit-1 independent. Endocrinology 138 1019-1028. (doi:10.1210/en. 138.3.1019) 
Carr FE, Shupnik MA, Burnside J \& Chin WW 1989 Thyrotropin-releasing hormone stimulates the activity of the rat thyrotropin beta-subunit gene promoter transfected into pituitary cells. Molecular Endocrinology 3 717-724. (doi:10.1210/mend-3-4-717)

von Gall C, Stehle JH \& Weaver DR 2002 Mammalian melatonin receptors: molecular biology and signal transduction. Cell and Tissue Research 309 151-162. (doi:10.1007/s00441-002-0581-4)

Giovannucci DR \& Stuenkel EL 1995 Glutamate receptor agonists modulate $\left[\mathrm{Ca}^{2+}\right] \mathrm{i}$ in isolated rat melanotropes. Neuroendocrinology 62 111-122. (doi:10.1159/000126995)

Gross DS 1984 The mammalian hypophysial pars tuberalis: a comparative immunocytochemical study. General and Comparative Endocrinology 56 283-298. (doi:10.1016/0016-6480(84)90043-1)

Hawkins RA, Dejoseph MR \& Hawkins PA 1995 Regional brain glutamate transport in rats at normal and raised concentrations of circulating glutamate. Cell and Tissue Research 281 207-214. (doi:10.1007/s004410050417)

Hazlerigg DG 2001 What is the role of melatonin within the anterior pituitary? Journal of Endocrinology 170 493-501. (doi:10.1677/joe.0. 1700493)

Herb A, Burnashev N, Werner P, Sakmann B, Wisden W \& Seeburg PH 1992 The KA-2 subunit of excitatory amino acid receptors shows widespread expression in brain and forms ion channels with distantly related subunits. Neuron 8 775-785. (doi:10.1016/0896-6273(92)90098-X)

Hinoi E \& Yoneda Y 2001 Expression of GluR6/7 subunits of kainate receptors in rat adenohypophysis. Neurochemistry International 38 539-547. (doi:10.1016/S0197-0186(00)00115-7)

Hinoi E, Takarada T, Ueshima T, Tsuchihashi Y \& Yoneda Y 2004 Glutamate signaling in peripheral tissues. European Journal of Biochemistry 271 1-13. (doi:10.1046/j.1432-1033.2003.03907.x)

Hollmann M \& Heinemann S 1994 Cloned glutamate receptors. Annual Review of Neuroscience 17 31-108. (doi:10.1146/annurev.ne.17.030194.000335)

Kawarai Y 1980 Identification of acth cells and TSH cells in rat anterior pituitary with the unlabeled antibody enzyme method on adjacent thin and thick sections. Acta Histochemica et Cytochemica 13 627-645. (doi:10.1267/ ahc.13.627)

Kiyama H, Sato K \& Tohyama M 1993 Characteristic localization of non-NMDA type glutamate receptor subunits in the rat pituitary gland. Brain Research. Molecular Brain Research 19 262-268. (doi:10.1016/0169328X(93)90039-R)

Klosen P, Bienvenu C, Demarteau O, Dardente H, Guerrero H, Pevet P \& Masson-Pevet M 2002 The $\mathrm{mt} 1$ melatonin receptor and RORbeta receptor are co-localized in specific TSH-immunoreactive cells in the pars tuberalis of the rat pituitary. Journal of Histochemistry and Cytochemistry 50 1647-1657. (doi:10.1177/002215540205001209)

Krass ME, LaBella FS \& Vivian SR 1968 Thyrotrophin release in vitro: the role of metabolism in the secretory response to vasopressin, oxytocin and epinephrine. Endocrinology 82 1183-1189. (doi:10.1210/ endo-82-6-1183)

Lam KS \& Wong RL 1999 Thyroid hormones regulate the expression of somatostatin receptor subtypes in the rat pituitary. Neuroendocrinology 69 460-464. (doi:10.1159/000054450)

Login IS 1990 Direct stimulation of pituitary prolactin release by glutamate. Life Sciences 47 2269-2275. (doi:10.1016/0024-3205(90)90158-N)

Mahesh VB, Zamorano P, De Sevilla L, Lewis D \& Brann DW 1999 Characterization of ionotropic glutamate receptors in rat hypothalamus, pituitary and immortalized gonadotropin-releasing hormone $(\mathrm{GnRH})$ neurons (GT1-7 cells). Neuroendocrinology 69 397-407. (doi:10.1159/ 000054442)

Masumoto KH, Ukai-Tadenuma M, Kasukawa T, Nagano M, Uno KD, Tsujino K, Horikawa K, Shigeyoshi Y \& Ueda HR 2010 Acute induction of Eya3 by late-night light stimulation triggers TSHbeta expression in photoperiodism. Current Biology 20 2199-2206. (doi:10.1016/j.cub.2010. 11.038)

Meeker RB, Greenwood RS \& Hayward JN 1994 Glutamate receptors in the rat hypothalamus and pituitary. Endocrinology 134 621-629. (doi:10.1210/ en.134.2.621)
Niimi M, Sato M, Murao K, Takahara J \& Kawanishi K 1994 Effect of excitatory amino acid receptor agonists on secretion of growth hormone as assessed by the reverse hemolytic plaque assay. Neuroendocrinology 60 173-178. (doi:10.1159/000126748)

Ono H, Hoshino Y, Yasuo S, Watanabe M, Nakane Y, Murai A, Ebihara S, Korf HW \& Yoshimura T 2008 Involvement of thyrotropin in photoperiodic signal transduction in mice. PNAS 105 18238-18242. (doi:10.1073/pnas.0808952105)

Pampillo M, Theas S, Duvilanski B, Seilicovich A \& Lasaga M 2002 Effect of ionotropic and metabotropic glutamate agonists and D-aspartate on prolactin release from anterior pituitary cells. Experimental and Clinical Endocrinology \& Diabetes 110 138-144. (doi:10.1055/s-2002-29092)

Petralia RS, Yokotani N \& Wenthold RJ 1994 Light and electron microscope distribution of the NMDA receptor subunit NMDAR1 in the rat nervous system using a selective anti-peptide antibody. Journal of Neuroscience $\mathbf{1 4}$ 667-696.

Reeds PJ, Burrin DG, Jahoor F, Wykes L, Henry J \& Frazer EM 1996 Enteral glutamate is almost completely metabolized in first pass by the gastrointestinal tract of infant pigs. American Journal of Physiology 270 E413-E418.

Reeds PJ, Burrin DG, Stoll B \& Jahoor F 2000 Intestinal glutamate metabolism. Journal of Nutrition 130 978S-982S.

Rivkees SA \& Reppert SM 1992 RFL9 encodes an A2b-adenosine receptor. Molecular Endocrinology 6 1598-1604. (doi:10.1210/me.6.10.1598)

de la Rosa V, Campos-Sandoval JA, Martin-Rufian M, Cardona C, Mates JM, Segura JA, Alonso FJ \& Marquez J 2009 A novel glutaminase isoform in mammalian tissues. Neurochemistry International 55 76-84. (doi:10.1016/j. neuint.2009.02.021)

Rudolf T, Filler T \& Wittkowski W 1993 Pars tuberalis specific cells within the pars distalis of the adenohypophysis. An ontogenetic study. Annals of Anatomy 175 171-176. (doi:10.1016/S0940-9602(11)80177-9)

Sakai T, Inoue K \& Kurosumi K 1992 Light and electron microscopic immunocytochemistry of TSH-like cells occurring in the pars tuberalis of the adult male rat pituitary. Archives of Histology and Cytology 55 151-157. (doi:10.1679/aohc.55.151)

Sakamoto S, Nakamura K, Inoue K \& Sakai T 2000 Melatonin stimulates thyroid-stimulating hormone accumulation in the thyrotropes of the rat pars tuberalis. Histochemistry and Cell Biology 114 213-218. (doi: 10.1007/ s004180000188)

Samuels MH, Henry P \& Ridgway EC 1992 Effects of dopamine and somatostatin on pulsatile pituitary glycoprotein secretion. Journal of Clinical Endocrinology and Metabolism 74 217-222. (doi:10.1210/jc.74.1.217)

Shupnik MA \& Ridgway EC 1985 Triiodothyronine rapidly decreases transcription of the thyrotropin subunit genes in thyrotropic tumor explants. Endocrinology 117 1940-1946. (doi:10.1210/endo-117-5-1940)

Stehle JH, Rivkees SA, Lee JJ, Weaver DR, Deeds JD \& Reppert SM 1992 Molecular cloning and expression of the cDNA for a novel A2-adenosine receptor subtype. Molecular Endocrinology 6 384-393. (doi:10. 1210/me.6.3.384)

Sugawara M, Nakanishi T, Fei YJ, Huang W, Ganapathy ME, Leibach FH \& Ganapathy V 2000 Cloning of an amino acid transporter with functional characteristics and tissue expression pattern identical to that of system A. Journal of Biological Chemistry 275 16473-16477. (doi:10.1074/jbc. C000205200)

Unfried C, Ansari N, Yasuo S, Korf HW \& von Gall C 2009 Impact of melatonin and molecular clockwork components on the expression of thyrotropin beta-chain (Tshb) and the Tsh receptor in the mouse pars tuberalis. Endocrinology 150 4653-4662. (doi:10.1210/en.2009-0609)

Wakabayashi K \& Tanaka S 1988 Assessment of specificity of antisera for immunohistochemistry. Acta Histochemica et Cytochemica 21 221-229. (doi:10.1267/ahc.21.221)

Wang L, Maher TJ \& Wurtman RJ 2007 Oral L-glutamine increases GABA levels in striatal tissue and extracellular fluid. FASEB Journal 21 1227-1232. (doi:10.1096/fj.06-7495com)

Watanabe M, Yasuo S, Watanabe T, Yamamura T, Nakao N, Ebihara S \& Yoshimura T 2004 Photoperiodic regulation of type 2 deiodinase gene in 
Djungarian hamster: possible homologies between avian and mammalian photoperiodic regulation of reproduction. Endocrinology 145 1546-1549. (doi:10.1210/en.2003-1593)

Weaver DR, Rivkees SA \& Reppert SM 1989 Localization and characterization of melatonin receptors in rodent brain by in vitro autoradiography. Journal of Neuroscience 9 2581-2590.

Williams LM \& Morgan PJ 1988 Demonstration of melatonin-binding sites on the pars tuberalis of the rat. Journal of Endocrinology 119 R1-R3. (doi:10. 1677/joe.0.119R001)

Yoneda Y \& Ogita K 1986 [3H]glutamate binding sites in the rat pituitary Neuroscience Research 3 430-435. (doi:10.1016/0168-0102(86)90034-9)

Yoshimura T, Yasuo S, Watanabe M, Iigo M, Yamamura T, Hirunagi K \& Ebihara S 2003 Light-induced hormone conversion of $T_{4}$ to $T_{3}$ regulates photoperiodic response of gonads in birds. Nature 426 178-181. (doi:10. 1038/nature02117)
Zanisi M, Galbiati M, Messi E \& Martini L 1994 The anterior pituitary gland as a possible site of action of kainic acid. Proceedings of the Society for Experimental Biology and Medicine 206 431-437. (doi:10.3181/0037927206-43783)

Zoeller RT, Tan SW \& Tyl RW 2007 General background on the hypothalamic-pituitary-thyroid (HPT) axis. Critical Reviews in Toxicology 37 11-53. (doi:10.1080/10408440601123446)

Received in final form 22 December 2011

Accepted 4 January 2012

Made available online as an Accepted Preprint 4 January 2012 